\title{
The Influence of Dietary Salt on the Osseointegration of Implants in Aging Rats
}

\author{
Julio Baldisserotto ${ }^{1,2}$ \\ ${ }^{1}$ Faculty of Dentistry, Universidade Federal do Rio Grande do Sul, \\ Porto Alegre, RS, Brazil \\ 2 Postgraduation Program of Health Technology Assessment, Grupo \\ Hospitalar Conceição, Porto Alegre, RS, Brazil \\ 3 Faculty of Dentistry, Sector of Health Sciences, Universidade Federal \\ do Parana, Curitiba, PR, Brazil
}

Int Arch Otorhinolaryngol 2019;23:e427-e432.

\author{
José Miguel Amenábar ${ }^{3}$
}

\begin{abstract}
Address for correspondence Julio Baldisserotto, DDS, PhD, MSc, Faculdade de Odontologia, Universidade Federal do Rio Grande do Sul., Rua Ramiro Barcelos 2492 $/ 3^{\circ}$ and Porto Alegre, Porto Alegre, RS 90040-060, Brazil (e-mail: jbaldisserotto@gmail.com).
\end{abstract}

\begin{abstract}
Keywords

- osseointegration

- sodium chloride

- bone density

- bone-implant interface

Introduction The bone-implant interface has been studied extensively, but only few papers focused on the nutritional aspects that may affect bone quality, especially salt intake.

Objective To study the osseointegration of implants in salt-loaded rats with low mineral bone content.

Methods A total of 604 -month-old male rats were divided in 2 groups $(n=30)$, being these groups divided in 2 periods, ( 2 and 4 months). The control group received a normal diet, while the test group received a diet supplemented with $1 \%$ sodium chloride $(\mathrm{NaCl})$. Implants were placed in the tibia of both groups. A total of 15 animals of each group were sacrificed at the $2^{\text {nd }}$ month of the experiment, while the remaining animals were sacrificed at the $4^{\text {th }}$ month.

Results No statistically significant difference was found in food intake between the groups on any experimental period, but a statistically significant difference was found in the liquid intake in the saline group in both periods. For all groups, osseointegration was observed in both groups. The mean percentage of osseointegration in the cortical bone, in the trabecular bone, and in the total osseointegrated surface between the control $(46.38 \pm 16.17 \%)$ and saline $(49.13 \pm 11.52 \%)$ groups at 2 months was not statistically different $(p=0.61)$. The total osseointegration areas of the control $(53.98 \pm 12.06 \%)$ and saline $(51.40 \pm 13.01 \%)$ groups at the $4^{\text {th }}$ month of the study were not statistically $(p=0.61)$.

Conclusion Ingestion of salt did not affect directly the osseointegration process during the period of the experiment. The results suggest that mineral losses may not affect the achievement of good osseointegration in aging rats.
\end{abstract}

\section{Introduction}

Many epidemiological studies about oral health status in populations have demonstrated a direct relationship between the number of edentulous people and their age, as well as an inverse relationship between the number of teeth in mouth and age, ${ }^{1,2}$ which would mean an increase in the needs for dental implants in the elderly. ${ }^{3}$

received

November 23, 2018

accepted

May 23, 2019
DOI https://doi.org/

10.1055/s-0039-1693141. ISSN 1809-9777.
The osseointegration concept and its application in clinical dentistry have been widely used in modern dentistry, especially for edentulous people. According to Bränemark, osseointegration can be defined as a structural and functional direct connection between a live bone and an implant surface under functional load. ${ }^{4}$ Schroeder clearly demonstrated the direct anchorage between the implant surface and the bone. ${ }^{5}$ The interface between bone and implant has been considered the
Copyright $(2019$ by Thieme Revinter Publicações Ltda, Rio de Janeiro, Brazil
License terms

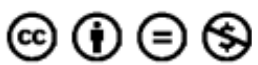


key point for osseointegration. Many studies have been made to analyze its structure in the macroscopic, microscopic, and ultrastructural levels. $^{6}$

The literature related to the indication of implants in patients with low bone quality is controversial, specifically in relation to osteoporosis. ${ }^{7,8}$ In spite of the fact that osteoporosis results in a loss of bone mass, especially in long bones, the repairing and healing process may occur normally. ${ }^{9}$

Nutrition deficiency, especially calcium (Ca) deficiency, has been considered one of the risk factors for bone loss in humans. ${ }^{10}$ The typical Western diet is rich in proteins, in salt, and in processed foods, which could contribute to the increased incidence of osteoporosis. ${ }^{11}$ In many Western countries, the ingestion of salt is considered high ( $\sim 10 \mathrm{~g} /$ day), and a moderate reduction in salt intake (to $4 \mathrm{~g} /$ day) would lower blood pressure and Ca excretion. ${ }^{12}$ The effects of sodium are explained by the fact that sodium and Ca have a shared transport mechanism in the renal proximal tubules. Any increase in the filtering of one ion would lead to an increase in the excretion of the other. ${ }^{13-15}$ Several authors agree that the high ingestion of sodium chloride $(\mathrm{NaCl})$ causes an increase in the loss of Ca through urine, and that it reduces the mineral composition of the bone, thus affecting the balance of Ca in the organism. ${ }^{16-19}$ The increase in the consumption of salt also produces an increase in the urinary excretion of hydroxyproline, indicating an increase of the bone resorption process. ${ }^{20-22}$

During the aging process, some physiological modifications occur in the mouth of the elderly individual. Loss of gustative capacity is one of them, and it has been related to an increase in sugar and salt consumption by the elderly. ${ }^{23}$ Low salivary flow and xerostomia are other factors that are associated with an increase in the taste preferences for salty and acid foods by the elderly. Galili demonstrated that animals with induced xerostomia preferred a salty diet. ${ }^{24}$ It is also well-known that elderly people are a group that consumes a very high amount of medications. A great proportion of these medications have as side effects xerostomia or a decrease in the salivary flow, ${ }^{25}$ which might be responsible for an increased $\mathrm{NaCl}$ intake in the elderly group of the population.

Another issue, which should be pointed out, is that nutritional status is related to oral health status. Many investigations have demonstrated a clear relationship between masticatory efficiency and nutritional deficiency. ${ }^{26,27}$ Epidemiological data showed that many aged people have a poor oral health status that results in a reduction in the masticatory capacity. ${ }^{28-30}$ The altered taste perception influences the preferences for salty food. Elderly people, especially those in a poor health status, are more likely to eat a salty diet.

Researches have been made to relate the mineral density of the bone and bone resorption as a consequence of the ingestion of salt. The bone density of the femur, of the tibia, and of the vertebrae in mice has been investigated. ${ }^{31}$ Mice fed with a high-salt diet presented a decrease of $5.5 \%$ in the bone density of different bones. Similar results in terms of reduction of the Ca content in the bone were found in other studies. ${ }^{21,32}$ Chan et al clearly demonstrated in rats that the Ca metabolism and its concentration in the bone suffered alterations when the animals were submitted to different levels of salt ingestion. They concluded that the high consumption of salt causes an increase in the loss of $\mathrm{Ca}$ and a reduction of the content of $\mathrm{Ca}$ in the bone. ${ }^{32}$ Although the relationship between salt intake and Ca excretion has been reported, the influence of different nutrients, especially $\mathrm{NaCl}$, on the osseointegration process, was not found in the literature.

The objective of the present investigation is to analyze the effects of high $\mathrm{NaCl}$ ingestion on the osseointegration process around titanium implants in an aging rats model experiment.

\section{Material and Methods}

\section{Experimental Animals and Study Design}

Few animal models are available to study the effect of novel implant surface modifications in osteoporotic conditions. Laboratory rats comply with several practical advantages, including the reliability of several methods for rapid induction of osteoporotic conditions. ${ }^{33,34}$ Therefore, Wistar rats were used in the present study.

A total of 60 4-month-old male rats were obtained from a biological research institute. All of the animals were housed under conditions of controlled temperature $\left(23 \pm 2^{\circ} \mathrm{C}\right)$ and artificial light (12-hour light/dark) cycle.

The animal research model of the present study follows the guidelines and international principles of biomedical research in animals (World Health Organization-United Nations Educational, Scientific and Cultural Organization [WHO-UNESCO]), ${ }^{35}$ and has been approved by the scientific and ethical committee of São Lucas Hospital of Pontificia Universidade Católica of Rio Grande do Sul.

The rats were randomly divided in $2 \times 4$ groups ( 60 days and 120 days groups $)^{36}$ of 15 animals each, and they were all fed with a normal diet of standard pellets (Nuvital Nutrientes Ltda., Colombo, PR, Brazil) containing 1\% of $\mathrm{NaCl}$ and $0.45 \%$ of $\mathrm{Ca}$. Group A (control) received the normal diet and distilled water, both ad libitum. Group B (experimental) received the normal diet and a saline solution ( $1 \%$ $\mathrm{NaCl}),{ }^{37,38}$ both also ad libitum. We have shown in a previous study that rats submitted to the same saline solution had a reduction in the bone mineral content in the tibia. ${ }^{39}$ Both liquid ingestion and food consumption were measured weekly. The animals were weighted at the beginning of the experiment and in the day of the sacrifice.

\section{Implants and Surgical Procedures}

Screw-shaped implants made of commercially pure titanium were machined in an identical manner (titanium content, 99.66\%; Conexão Sistemas de Prótese, São Paulo, SP, Brazil). The total length of each implant was $3.5 \mathrm{~mm}$; the thread diameter was $1.8 \mathrm{~mm}$, and the pitch was $1 \mathrm{~mm}$. The implants were cleaned and sterilized by the manufacturer.

The rats were anesthetized by abdominal administration of $0.1 \mathrm{ml} / \mathrm{kg}$ of a 1:1 mixture of ketamine chloride (Ketamina; Virbac, São Paulo, SP, Brazil) and tiazine (Rompun; Bayer, São Paulo, SP, Brazil). The animals were then divided equally into test (salt solution) and control (water) groups with 2 and 4 months of duration of the experiment. 
An implant was placed in the proximal metaphysis of the tibia in each animal 60 days after the saline solution was initiated. After general anesthesia, the bone surface of the tibia was exposed by an incision $\sim 10 \mathrm{~mm}$ long. Under profuse saline irrigation, the implantation hole was drilled at a low rotation speed; the implant was then inserted into the hole.

A total of 15 rats of each group were sacrificed by decapitation under anesthesia (described above) at 60 and 120 days after the implantation, and the implants were removed along with bone tissue and fixed in $10 \%$ buffered formaldehyde.

\section{Sample Preparation and Analysis}

The specimens were dehydrated and embedded in Technovit 7100 glycol methacrylate resin (Kulzer Technik, Wehrleim, Germany). One sagittal undecalcified ground section was prepared along the axis of the implant. Cuts were made using the method described by Padilha et al. ${ }^{40}$ Each section was stained with $1 \%$ toluidine blue and inspected under a B201 light microscope (Olympus, Tokyo, Japan). ${ }^{41}$

Photographs of each specimen were taken with a B201stereomicroscope (Olympus, Tokyo, Japan) in 50x magnification using a conventional Kodak ULTRA 135, ASA 100 film (Kodak, Rochester, NY, USA). Afterwards, the photographs were digitized with an Epson Expression 636 desk scanner (Epson, Suwa, Japan).

The implant-bone contacts were morphometrically evaluated according to the following primary parameters ( - Fig. $\mathbf{1}$ ):

- Total cortical bone contact $(\mathrm{mm})$ : the total amount of cortical bone in contact with the implant ( - Fig. 1, A + B; $\mathrm{C}+\mathrm{D} ; \mathrm{E}+\mathrm{F} ; \mathrm{G}+\mathrm{H})$.

- Total trabecular bone contact ( $\mathrm{mm})$ : the total amount of trabecular bone in contact with the implant ( $\mathbf{F i g . 1 , K}+\mathrm{L}$ ).

- Length around the implant $(\mathrm{mm})$ : length around the implant in the bone tissue.

- Total bone contact length ( $\mathrm{mm}$ ): the total amount of bone (cortical + trabecular) in contact with the implant.

- Bone contact rate (\%), calculated as follows: (total contact length/length around the implant) $x 100$. The same was applied for cortical and trabecular contact rate.

The primary parameters were measured from the digital images using the UTHSCSA Image Tool, version 2.02 automated imaging analytic system (Wilcox et al, University of Texas Health Science Center, San Antonio TX, USA).

The statistical analysis was conducted using the t-test for differences between the groups, and analysis of variance (ANOVA) to see the differences of the variables among the groups during the experimental period. The level of significance was $p<0.05$.

\section{Results}

During the experimental period, the animals were weighted at the day of the sacrifice. The mean weight of the control group was $395.33 \mathrm{~g}( \pm 32.73)$, while in the experimental group the mean weight was $403.38 \mathrm{~g}( \pm 31.56)$. No statistically significant difference was found between the groups.

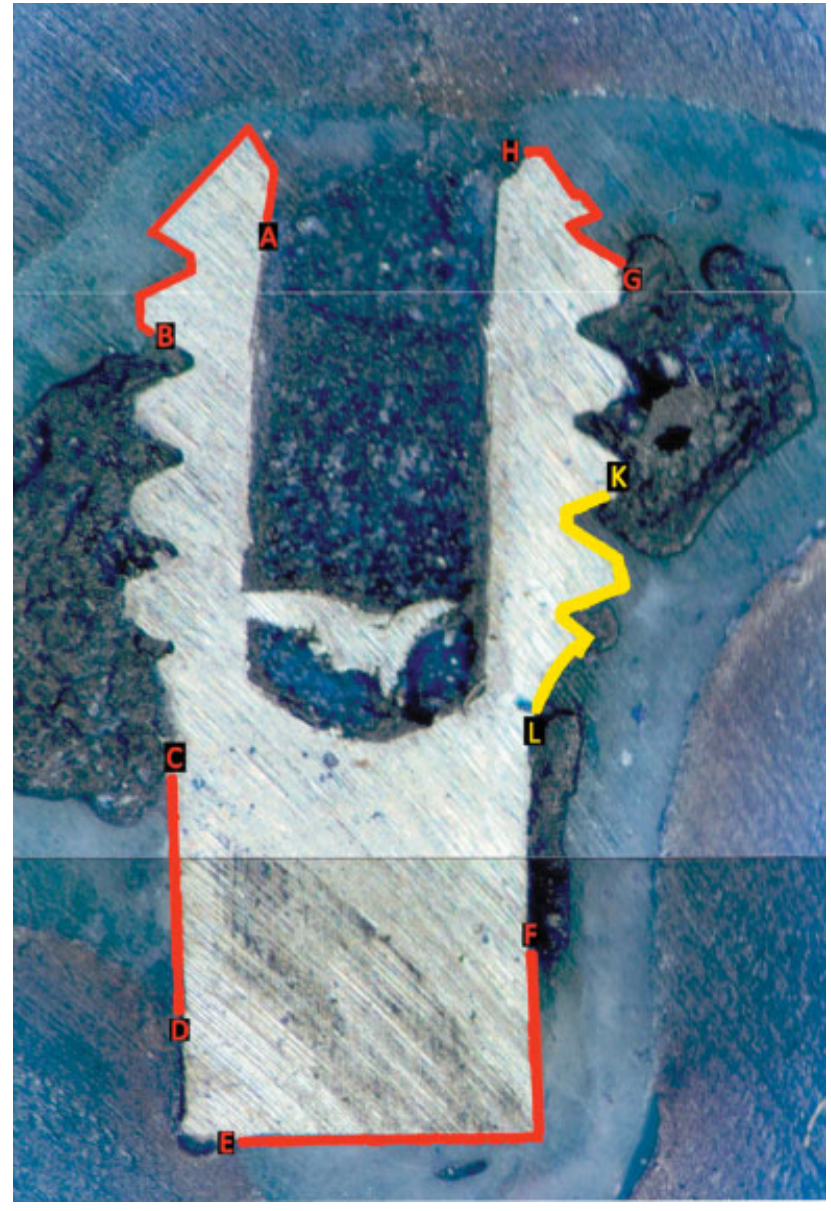

Fig. 1 Scheme of cortical and trabecular bone measures

All of the implant sites were mechanically tested and were found to be clinically stable. Also, no clinical findings of adverse reactions or of inflammation could be observed around the implants.

The animals did not show health complications in the surgical site during the experiment.

\section{Histologic Evaluation}

For all groups, areas of osseointegration in cortical and trabecular bone around the implant were seen on both the control and saline groups (-Fig. 2). The implant-bone contacts were morphometrically measured and expressed in percentages. - Table 1 shows that the mean percentage of osseointegration in both the control and saline groups were $38.70 \%$ and $38.11 \%$ in the cortical bone, and $7.69 \%$ and $11.02 \%$ in the trabecular bone, respectively, and that the total osseointegrated surface $(46.38 \pm 16.17 \%)$ and $(49.13 \pm 11.52 \%)$ at 2 months was not statistically different between the two groups $(p=0.61)$.

At 4 months after the insertion of the implant, the results showed that the mean percentage of osseointegration in both the control and saline groups were $46.92 \%$ and $41.18 \%$ in the cortical bone and $7.06 \%$ and $10.22 \%$ in the trabecular bone, respectively, and that the total osseointegrated implant surface $(53.98 \pm 12.06 \%)$ and $(51.40 \pm 13.01 \%)$ was not 


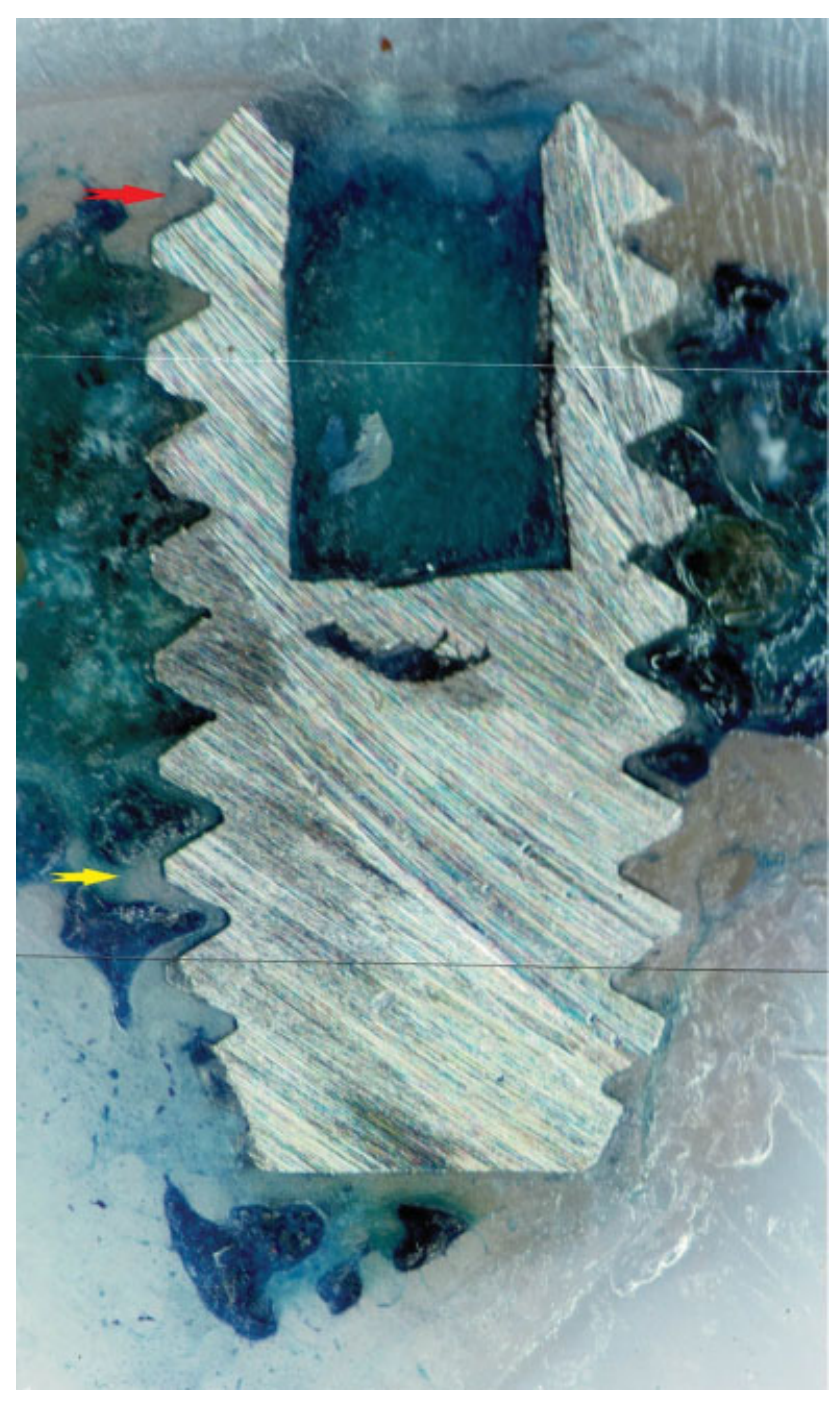

Fig. 2 Osseointegration areas in the cortical bone (red arrow) and in the trabecular bone (yelow arrow).

Table 1 Mean and standard deviation of the cortical bone, of the trabecular bone, and of the total osseointegrated implant surface (in percentages) of the control and saline groups at 2 months

\begin{tabular}{|l|l|l|l|}
\hline & Control & Saline & -value \\
\hline & $\begin{array}{l}\text { Mean } \pm \text { SD } \\
\boldsymbol{n}=\mathbf{1 5}\end{array}$ & $\begin{array}{l}\text { Mean } \pm \text { SD } \\
\boldsymbol{n}=\mathbf{1 5}\end{array}$ & \\
\hline Cortical bone & $38.70 \pm 17.50$ & $38.11 \pm 12.13$ & 0.92 \\
\hline Trabecular bone & $7.69 \pm 10.50$ & $11.02 \pm 10.81$ & 0.42 \\
\hline $\begin{array}{l}\text { Total } \\
\text { osseointegrated } \\
\text { implant surface }\end{array}$ & $46.38 \pm 16.17$ & $49.13 \pm 11.52$ & 0.61 \\
\hline
\end{tabular}

t-test $(p<0.05)$.

statistically significant the difference between the two groups ( $p=0.61$ ) as can be seen in - Table 2 .

- Table 3 shows a comparison of the osseointegration process between the 2 time periods ( 2 and 4 months) of the control group. It can be observed that an increase in the osseointegration area occurred in the cortical bone (38.70 to $46.92 \%$ ) and in the total osseointegrated implant surface
Table 2 Mean and standard deviation of the cortical bone, of the trabecular bone, and of the total osseointegrated implant surface (in percentages) of the control and saline groups at 4 months

\begin{tabular}{|l|l|l|l|}
\hline & Control & Saline & -value \\
\hline & $\begin{array}{l}\text { Mean } \pm \text { SD } \\
\boldsymbol{n}=\mathbf{1 5}\end{array}$ & $\begin{array}{l}\text { Mean } \pm \text { SD } \\
\boldsymbol{n}=\mathbf{1 5}\end{array}$ & \\
\hline Cortical bone & $46.92 \pm 12.47$ & $41.18 \pm 14.70$ & 0.30 \\
\hline Trabecular bone & $7.06 \pm 5.67$ & $10.22 \pm 11.54$ & 0.40 \\
\hline $\begin{array}{l}\text { Total } \\
\text { osseointegrated } \\
\text { implant surface }\end{array}$ & $53.98 \pm 12.06$ & $51.40 \pm 13.01$ & 0.61 \\
\hline
\end{tabular}

t-test $(p<0.05)$.

Table 3 Mean and standard deviation of the cortical bone, of the trabecular bone, and of the total osseointegrated implant surface (in percentages) of the control and saline groups at 2 and 4 months

\begin{tabular}{|l|l|l|l|}
\hline $\begin{array}{l}\text { Osseointegration } \\
\text { areas }\end{array}$ & $\begin{array}{l}2 \text { months } \\
\text { Mean } \pm \text { SD }\end{array}$ & $\begin{array}{l}4 \text { months } \\
\text { Mean } \pm \text { SD }\end{array}$ & $p$-value \\
\hline Cortical bone & & & \\
\hline Control & $38.70 \pm 17.50$ & $46.92 \pm 12.47$ & 0.18 \\
\hline Saline & $38.11 \pm 12.13$ & $41.18 \pm 14.70$ & 0.56 \\
\hline Trabecular Bone & & & \\
\hline Control & $7.69 \pm 10.50$ & $7.06 \pm 5.68$ & 0.85 \\
\hline Saline & $11.02 \pm 10.81$ & $10.22 \pm 11.54$ & 0.85 \\
\hline $\begin{array}{l}\text { Total } \\
\text { osseointegrated } \\
\text { implant surface }\end{array}$ & & & \\
\hline Control & $46.38 \pm 16.17$ & $53.98 \pm 12.06$ & 0.18 \\
\hline Saline & $49.13 \pm 11.52$ & $51.40 \pm 13.01$ & 0.64 \\
\hline
\end{tabular}

Analysis of variance $(p<0.05)$.

(46.38 to $53.98 \%$ ) with time, although this is not statistically significant ( $p=0.18$ ).

A similar pattern is observed in the saline group with time (2 and 4 months). The cortical bone contact (38.11 to $41.18 \%$ ) and the total osseointegrated implant surface (49.13 to $51.40 \%$ ) increased, but there was not a statistically significant difference $(p=0.64)$.

In both groups (control and saline), the total osseointegration improved with time, but the difference between the two time periods was not statistically significant.

The ANOVA test was applied to see differences on the percentages of cortical bone, trabecular bone, and total osseointegrated surface between the groups during the experimental period. No statistically significant difference was found.

\section{Discussion}

Although the bone-implant interface has been studied extensively, a very small number of papers have been concerned with the nutrition factors that may affect bone quality, both prior to the implant placement, as well as during the healing period. 
The quality of the bony bed has been evaluated by the necessary torque to remove the implant, but many factors are known to affect bone quality. ${ }^{42}$ Among these factors, nutrition deficiency, and especially calcium deficiency, has been considered a risk factor for bone loss in humans. ${ }^{10}$

The present study was conducted to obtain information regarding osseointegration of implants in rats with low mineral content induced by a dietary salt ingestion. Bone reaction after the placement of implants with time have been examined through the use of rat tibia at 60 and 120 days.

The body weight and the food consumption of the rats did not show a statistically significant difference between the control and experimental groups at different times. In relation to the liquid, the experimental group drank significantly more than the control group. These results show that the experimental animals had an even higher ingestion of salt through the saline solution. Since both groups had no difference in the amount of Ca intake from the food, this suggests that Ca losses from bone may not be replaced in the experimental group. According to our previous study, the ingestion of a salty diet can affect adversely the incorporation of bone mineral in rats receiving normal dietary Ca for a period of 4 months. ${ }^{39}$ Other studies also suggested that, in salt loaded rats, the lower bone Ca content is believed to have resulted from an increased urinary loss of Ca that was not compensated by a higher intestinal absorption. ${ }^{13,20}$

In long-term studies of the salt effect on bone, Cohen et al believe that an adaptive process in Ca homeostasis might take place. ${ }^{43}$ It has also been demonstrated elsewhere that the ingestion of $\mathrm{NaCl}$ for a long time did not affect the mineral content of the tibia in rats. ${ }^{39}$

Although the ingestion of salt can reduce the bone mineral content in the tibia of rats, we observed in the present study that the ingestion of salt did not affect directly the osseointegration process. Only a slight difference in bone contact between the implant and the new trabecular bone area is observed in the saline group at 60 and 120 days. This result could be expected due to the difficulties in measuring this osseointegration area. In spite of this fact, salt ingestion did not affect significantly the trabecular bone contact with the implant at 2 and 4 months after the implantation. When the same groups were compared with time, a statistically significant difference between groups was not found in relation to trabecular osseointegration areas. There was not a statistically significant difference for total osseointegration. On the other hand, a study done with osteoporotic-induced rats showed that a lower maxillary bone quality can reduce early bone formation on implant surfaces. ${ }^{44}$

In relation to the cortical bone contact with the implant, the results show that there was no statistically significant difference between the two groups at different times of the experiment. This suggests that mineral losses caused by high salt ingestion may not affect the achievement of good osseointegration, even if an implant is applied in a situation of lower bone quality. In contrast, Yamazaki found that in rats submitted to ovariectomy, a decrease in bone mass causes a reduction in the contact area between implant and bone, and may also cause a reduction in the supporting ability of the implant due to the thinning of the surrounding trabecular bone. $^{7}$

The healing process after the placement of implants into the tibiae of rats is known to reach completion $\sim 56$ days after the implantation. ${ }^{36}$ However, the effect of mineral losses caused by salt ingestion with time on bone remodeling around the implants has not been clear. In the present work, we have not found a statistically significant difference in a long-term study between the control and experimental group in terms of osseointegration. We have also found that new methods have been developed to improve the success rate of clinical dental implants in rat models with osteoporosis. ${ }^{45}$

Giro et al performed a systematic review focused on failure rates and percentages of osseointegration of dental implants in healthy and osteoporotic subjects and found that definitive conclusions regarding the impact of osteoporosis on dental implant therapy cannot be made at this time, and that it could be suggested that osteoporotic subjects can receive dental implant therapy. ${ }^{46}$ Another retrospective study comparing women with different osteoporosis status concluded that the diagnosis of osteopenia or of osteoporosis did not contribute to an increased risk of implant failure. ${ }^{47}$ Our study in animal models contributes with the idea that osteoporosis is not a clinical contraindication for dental implant treatment.

\section{Conclusions}

Despite the fact that a saline diet can affect the bone mineral content in the tibia of rats, the results demonstrated that there was no difference in osseointegration between the control and saline groups. To better elucidate the relationship between the pathologic changes in bone and in bone reactions around the implants due to salt intake, it is necessary to investigate in more details the effects of aging on the remodeling process of bone in the osseointegration site.

Conflicts of Interests

The authors have no conflicts of interests to disclose.

\section{References}

1 Kikutani T, Yoshida M, Enoki H, et al. Relationship between nutrition status and dental occlusion in community-dwelling frail elderly people. Geriatr Gerontol Int 2013;13(01):50-54

2 Colussi CF, Freitas SF. [Epidemiological aspects of oral health among the elderly in Brazil]. Cad Saude Publica 2002;18(05):1313-1320

3 Brasil. Ministério da Saúde. Secretaria de Atenção à Saúde. Secretaria de Vigilância em Saúde. SB BRASIL 2010; Pesquisa Nacional de Saúde Bucal. Resultados Principais. Brasília, 2012:118

4 Bränemark PI. Introdución a la Oseointegración. In: Bränemark PI, Albrektsson T. Protesis tejido-integradas: la osseointegración en la odontologia clínica. Berlin: Quintessence; 1987:11-76

5 Schroeder A, van der Zypen E, Stich H, Sutter F. The reactions of bone, connective tissue, and epithelium to endosteal implants with titanium-sprayed surfaces. J Maxillofac Surg 1981;9(01):15-25

6 Masuda T, Yliheikkilä PK, Felton DA, Cooper LF. Generalizations regarding the process and phenomenon of osseointegration. Part I. In vivo studies. Int J Oral Maxillofac Implants 1998;13(01):17-29

7 Yamazaki M, Shirota T, Tokugawa Y, et al. Bone reactions to titanium screw implants in ovariectomized animals. Oral Surg Oral Med Oral Pathol Oral Radiol Endod 1999;87(04):411-418 
8 Mori H, Manabe M, Kurachi Y, Nagumo M. Osseointegration of dental implants in rabbit bone with low mineral density. J Oral Maxillofac Surg 1997;55(04):351-361, discussion 362

9 Bryant SR, Zarb GA. Osseointegration of oral implants in older and younger adults. Int J Oral Maxillofac Implants 1998;13(04):492-499

10 Palacios C. The role of nutrients in bone health, from A to Z. Crit Rev Food Sci Nutr 2006;46(08):621-628. Doi: 10.1080/ 10408390500466174

11 Packard PT, Heaney RP. Medical nutrition therapy for patients with osteoporosis. J Am Diet Assoc 1997;97(04):414-417

12 MacGregor GA, Cappuccio FP. The kidney and essential hypertension: a link to osteoporosis? J Hypertens 1993;11(08):781-785

13 Nordin BEC, Need AG, Steurer T, Morris HA, Chatterton BE, Horowitz M. Nutrition, osteoporosis, and aging. Ann N Y Acad Sci 1998;854:336-351

14 Heaney RP. Calcium. In: Bilezikian JP, Raisz LG, Rodan GA. Principles of Bone Biology. San Diego: Academic Press; 199672:1007-1017

15 Nordin BEC, Need AG, Morris HA, Horowitz M. The nature and significance of the relationship between urinary sodium and urinary calcium in women. J Nutr 1993;123(09):1615-1622

16 Caudarella R, Vescini F, Rizzoli E, Francucci CM. Salt intake, hypertension, and osteoporosis. J Endocrinol Invest 2009;32 (4, Suppl)15-20

17 Greger JL, Tseng E. Longitudinal changes during the development of hypertension in rats fed excess chloride and sodium. Proc Soc Exp Biol Med 1993;203(03):377-385

18 Navidi M, Wolinsky I, Fung P, Arnaud SB. Effect of excess dietary salt on calcium metabolism and bone mineral in a spaceflight rat model. J Appl Physiol (1985) 1995;78(01):70-75

19 Chan EL, Swaminathan R. Effect of different amounts of sodium intake for 4 months on calcium metabolism in normal and oophorectomized rats. J Bone Miner Res 1993;8(10):1185-1189

20 Antonios TF, MacGregor GA. Salt intake: potential deleterious effects excluding blood pressure. J Hum Hypertens 1995;9(06):511-515

21 Goulding A, McIntosh J. Effects of $\mathrm{NaCl}$ on calcium balance, parathyroid function and hydroxyproline excretion in prednisolone-treated rats consuming low calcium diet. J Nutr 1986;116(06):1037-1044

22 Mason RA, Morris HÁ. Increased urinary calcium excretion potentiates bone turnover in oophorectomized rats. Miner Electrolyte Metab 1997;23(01):38-42

23 Brunetti RF, Montenegro FLB. Odontogeriatria: noções de interesse clínico. São Paulo. Art Med 2002;1:3-26

24 Galili D, Maller O, Brightman VJ. Effects of drug-desalivation on feeding and taste preferences in the rat. Arch Oral Biol 1978;23 (06):459-464

25 Pereira CMMS, Montenegro FLB. Efeitos bucais das drogas: cuidados na terceira idade. In: Brunetti RF, Montenegro FLB. Odontogeriatria: noções de interesse clínico. São Paulo: Artes Médicas; 20029:133-150

26 Rodrigues HL Jr, Scelza MF, Boaventura GT, Custódio SM, Moreira EA, Oliveira DdeL. Relation between oral health and nutritional condition in the elderly. J Appl Oral Sci 2012;20(01):38-44 Feb.

27 Dormenval $\mathrm{V}$, Budtz-Jørgensen $\mathrm{E}$, Mojon $\mathrm{P}$, Bruyère $\mathrm{A}$, Rapin $\mathrm{CH}$. Nutrition, general health status and oral health status in hospitalised elders. Gerodontology 1995;12(12):73-80

28 Samnieng P, Ueno M, Shinada K, Zaitsu T, Wright FA, Kawaguchi Y. Oral health status and chewing ability is related to mini-nutritional assessment results in an older adult population in Thailand. J Nutr Gerontol Geriatr 2011;30(03):291-304

29 Brennan DS, Spencer AJ, Roberts-Thomson KF. Tooth loss, chewing ability and quality of life. Qual Life Res 2008;17(02):227-235
30 Ekelund R. Dental state and subjective chewing ability of institutionalized elderly people. Community Dent Oral Epidemiol 1989; 17(01):24-27

31 Lalande A, Roux C, Graulet AM, Schiavi P, De Vernejoul MC. The diuretic indapamide increases bone mass and decreases bone resorption in spontaneously hypertensive rats supplemented with sodium. J Bone Miner Res 1998;13(09):1444-1450

32 Chan EL, Swaminathan R. Calcium metabolism and bone calcium content in normal and oophorectomized rats consuming various levels of saline for 12 months. J Nutr 1998;128(03):633-639

33 Alghamdi H, van den Beucken JJP, Jansen JA. Osteoporotic Rat Models for Evaluation of Osseointegration of Bone Implants. Tissue Eng Part C Methods 2013;•..;

34 Beppu K, Kido H, Watazu A, Teraoka K, Matsuura M. Peri-implant bone density in senile osteoporosis-changes from implant placement to osseointegration. Clin Implant Dent Relat Res 2013;15(02): 217-226

35 Council for International Organizations of Medical Sciences. International Guiding Principles for Biomedical Research Involving Animals. In: Mapple TA. Degrazia D. Biomedical Ethics. 5 ed. McGraw-Hill Higher Ed. 1999:237-238

36 Shirota T, Ohno K, Suzuki K, Michi K. The effect of aging on the healing of hydroxylapatite implants. J Oral Maxillofac Surg 1993; 51(01):51-56

37 Miura N, Suzuki S, Hamada Y, et al. Salt water promotes hypertension in Dahl-S rats. Exp Anim 1999;48(04):289-292

38 Futterleib A, Padilha DM. Excessive sodium chloride intake on condyle morphology in aging rats [dissertation]. Pontificia Universidade Catolica do Rio Grande do Sul. 2004

39 Baldisserotto J, Padilha DMP, Souza ACA. Effects of salt intake on the mineral bone content of aging rat's tibia using a dual energy X-ray absorptiometry [thesis]. Pontificia Universidade Catolica do Rio Grande do Sul. 2003

40 Padilha DMP, Hammes M. Mesa milimétrica para corte de tecidos duros. Rev Fac Odontol P Alegre 1998;39(02):24-25

41 Chappard D, Grizon F, Brechet I, Baslé MF, Rebel A. Evolution of the bone-titanium interface on implants coated/noncoated with xenogeneic bone particles: quantitative microscopic analysis. J Biomed Mater Res 1996;32(02):175-180

42 Javed F, Ahmed HB, Crespi R, Romanos GE. Role of primary stability for successful osseointegration of dental implants: Factors of influence and evaluation. Interv Med Appl Sci 2013;5(04):162-167

43 Cohen AJ, Roe FJC. Review of risk factors for osteoporosis with particular reference to a possible aetiological role of dietary salt. Food Chem Toxicol 2000;38(2-3):237-253

44 Doan N, Du Z, Xiao J, et al. An Evaluation on the Effect of Osteoporosis on Osseointegration Around Titanium Implants in Posterior Maxilla Following a Tooth Extraction. In: Vo Van T, Nguyen Le T, Nguyen Duc T (eds) 6th International Conference on the Development of Biomedical Engineering in Vietnam (BME6). BME 2017; IFMBE Proceedings, vol 63. Springer, Singapore.

45 Duan Y, Ma W, Li D, Wang T, Liu B. Enhanced osseointegration of titanium implants in a rat model of osteoporosis using multilayer bone mesenchymal stem cell sheets. Exp Ther Med 2017;14(06): 5717-5726. Doi: 10.3892/etm.5303

46 Giro G, Chambrone L, Goldstein A, et al. Impact of osteoporosis in dental implants: A systematic review. World J Orthop 2015;6(02): 311-315. Doi: 10.5312/wjo.v6.i2.311

47 Holahan CM, Koka S, Kennel KA, et al. Effect of osteoporotic status on the survival of titanium dental implants. Int J Oral Maxillofac Implants 2008;23(05):905-910 